\title{
Mus musculus castaneus
}

National Cancer Institute

\section{Source}

National Cancer Institute. Mus musculus castaneus. NCI Thesaurus. Code C71623.

A subspecies of common house mouse (Mus musculus). 